\title{
ENSAIO FOTOETNOGRÁFICO
}

Mulheres quebradeiras de coco babaçu na Zona Rural de Teresina, Piauí

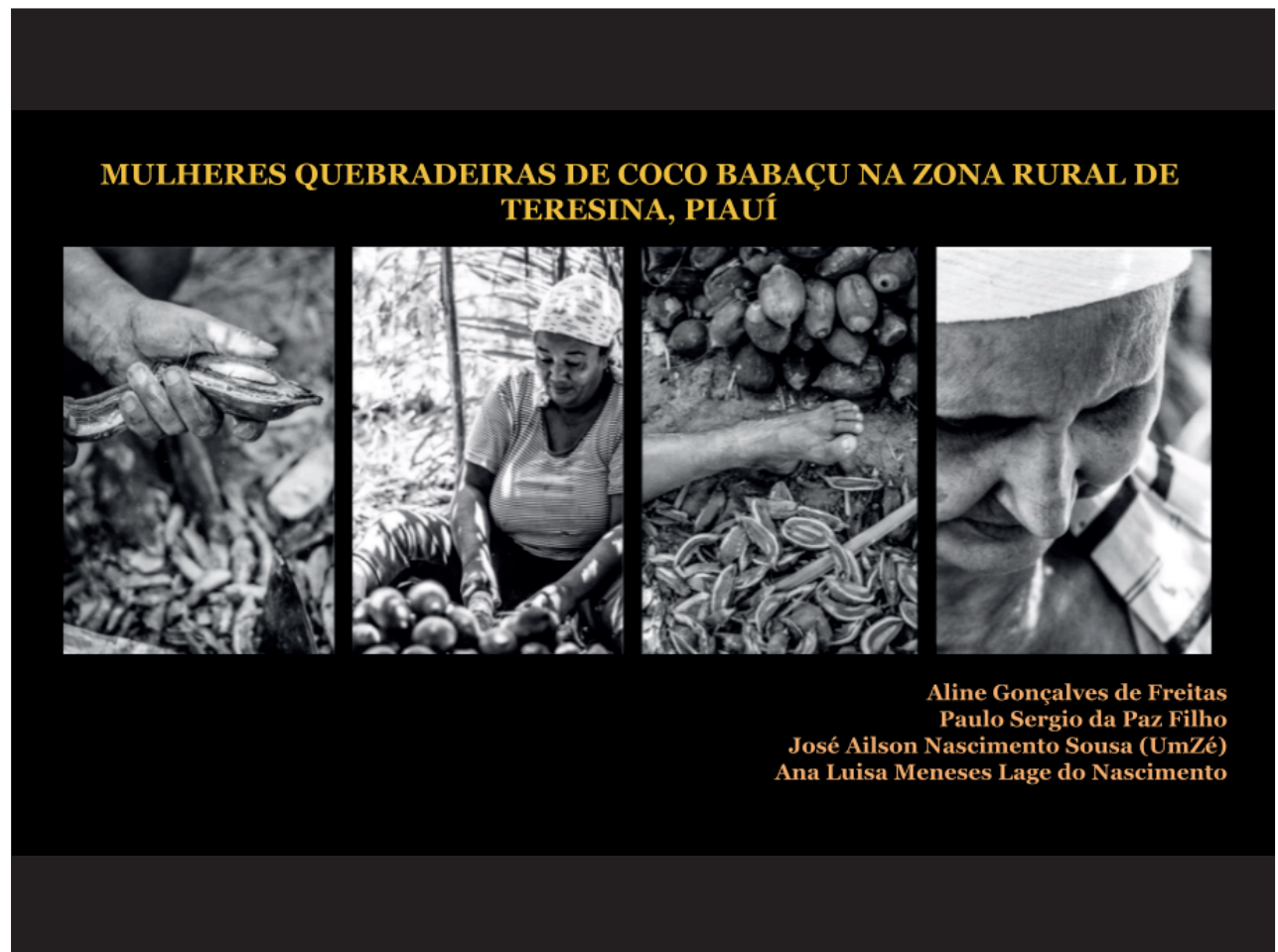

2021

Volume 7, Coleção 1 (n.1)

ISSN: 2525 - 3781
Aline Gonçalves Freitas

Ana Luisa Meneses Lage do Nascimento Paulo Sergio da Paz Filho

Sinopse:

Este ensaio apresenta os aspectos cotidianos das pessoas quebradeiras de coco da palmeira babaçu (Attalea speciosa Mart. Ex Spreng) na Comunidade Fazenda Soares, Zona Rural de Teresina (km 35,2 da Estrada Teresina-União), no Estado do Piauí. O azeite de babaçu é um produto vegetal de extrema importância econômica na Região Norte e Nordeste brasileiras, ocorrente nos cerrados dos Estados do Pará, Maranhão, Piauí, Tocantins e Bahia. Em sua grande maioria, as mulheres são as pessoas envolvidas neste ofício.

As etapas da produção do azeite de babaçu consistem em selecionar os cocos, quebrá-los, selecionar as amêndoas para a extração do azeite e usar as cascas (endocarpos) para fazer carvão. Observa-se assim os múltiplos usos de seus espaços territoriais (moradia e atividades de produção), os padrões de subsistência das pessoas envolvidas neste processo (Silva, 2011: 13) e o significado cultural que a palmeira babaçu possui para essas pessoas. Dona Maria Oneide e a Dona Francisca são duas das muitas mulheres da Comunidade que vivem da socioeconomia do babaçu. Como Elas mesma dizem: "uma tarefa dura mas ainda necessária" do ponto de vista da subsistência mas também do lucro obtido da venda do azeite, que constitui a base e/ou completo da renda de muitas famílias, no local. Às quintas-feiras, Elas adentram à mata adjacente à suas casas. Elas visam uma coleta sustentável, selecionando os cocos caídos e assim protegendo os babaçuais. Os "cocos" bons são agrupados em um local seco e sombrea 
do dentro da própria mata, uma espécie de cabana coberta por palhas, folhas e galhos. Às sextas-feiras, bem cedo, essas mulheres realizam a quebração de coco babaçu para a extração de suas amêndoas. O trabalho de retirada as amêndoas (sementes) do coco babaçu requer habilidade, pois são muitos cocos para quebrar para se obter poucas amêndoas, além de ser perigoso, já que usa-se um machado afiado e um pedaço de pau. Após a quebração dos cocos, as cascas são utilizadas como carvão vegetal. Os "cocos secos" são depositados em buracos (caieiras) feitos no solo e incinerados. Após alguns dias são retirados em ensacados e armazenados para consumo próprio e/ou comercialização. Durante as quatro horas em que acompanhamos o trabalho das quebradeiras também ouvimos suas histórias de vida e vivências com as plantas locais utilizadas.

Sexta-feira à tarde é feita a extração do azeite de babaçu, na cozinha da própria casa das mulheres responsáveis pela quebração dos cocos. Dona Eva, a matriarca da família e mãe de Dona Maria Oneide, devido à sua idade avançada já não vai para a mata coletar mas aguarda a coleta da filha e sua amiga para a produção do azeite.

A Dona Eva "ajunta" e torra as amêndoas enquanto Dona Maria Oneide as mói. Por isso que se diz que o azeite de babaçu é "queimado". Logo levam a pasta de amêndoas trituradas ao fogo à lenha para cozinhar. À medida que vai fervendo, o azeite vai "boiando" e Dona Eva "apura" todo o azeite de babaçu e o recolhe com todo cuidado e precisão para a Dona Maria Oneide o engarrafar. $\mathrm{O}$ azeite está pronto para seu uso e comercialização. A Família de Dona Eva nos surpreendeu com uma farofa de gongo ou bicho-do-coco (Pachymerus nucleorum), uma larva de besouro da família dos bruquídeos que vive nos frutos da palmeira babaçu que foi frito, é claro, no próprio azeite de babaçu.

Assim fomos percorrendo e delimitando os locais de atividade econômica e os saberes e fazeres do extrativismo do babaçu e de seus subprodutos, por parte dessas mulheres. Observamos suas relações sustentáveis com a natureza e do quanto a sociedade civil precisa alertar para a máxima urgência na preservação desse patrimônio cultural e ambiental (Pelegrini, 2006).

\section{Synopsis:}

Este artículo presenta algunos aspectos cotidianos de las personas que parten el coco de la palma babasú (Attalea speciosa Mart. Ex Spreng) en la Comunidad Fazenda Soares dentro del Área Rural de Teresina (km 35,2 de la Carretera Teresina-União) en la Província de Piauí. El aceite de babasú es un producto vegetal de gran importancia económica en las regiones Norte y Noreste de Brasil, presente en el cerrado de las Províncias de Pará, Maranhão, Piauí, Tocantins y Bahia. En su mayor parte, son las mujeres las personas involucradas en este oficio.

Las etapas de producción del aceite de babasú incluyen la selección de los cocos, después deben partirse, seleccionar las almendras para la extracción del aceite y finalmente utilizar las cáscaras (endocarpos) para hacer carbón. Así, es posible observar la multiplicidad de usos en sus espacios territoriales (vivienda y actividades productivas), los patrones de subsistencia de las personas involucradas en el procesado (Silva, 2011: 13) y el significado cultural que tiene la palma babasú para ellas.

Doña Maria Oneide y Doña Francisca son dos mujeres de la Comunidad que viven de la socioeconomía del babasú. Como ellas mismas dicen: "una tarea dura pero todavía necesaria" desde el punto de vista de la subsistencia, pero también del beneficio que se obtiene de la venta del aceite de babasú, la cual representa la base, si no la renta completa de muchos lugareños.

Cada jueves Maria y Francisca se adentran en el bosque que hay en las proximidades de su vivienda. Su objetivo es la recolección sostenible, seleccionando cocos caídos y protegiendo así los babasúais. Los "cocos buenos" se agrupan en un lugar seco y sombreado bajo la cubierta forestal, una especie de choza cubierta de paja, hojas y ramas. Los viernes, muy temprano, estas mujeres parten el coco babasú para extraer sus almendras.

El trabajo de sacar las almendras (semillas) del coco babasú requiere habilidad, ya que hay que romper muchos cocos para sacar pocas almendras. Por otro lado, es una tarea peligrosa, ya que se utilizan un hacha afilada y un palo. Después de romper los cocos, las cáscaras son utilizadas como carbón. 
Los "cocos secos" se depositan en agujeros (caieiras) hechos en el suelo y luego se incineran. Pasados unos días, se retiran los carbones en bolsas y se almacenan para consumo y/o comercialización. Durante las cuatro horas en las que seguimos el trabajo de las rompedoras, también escuchamos historias sobre sus vidas y experiencias con las plantas útiles del lugar. Los viernes, en la cocina, toca la extracción del aceite de babasú. Doña Eva, matriarca de la familia y madre de Doña Maria Oneide, debido a su avanzada edad, ya no va al bosque a recolectar sino que espera en casa la recolección de su hija y su amiga para la producción del aceite. Doña Eva recoge y tuesta las almendras mientras doña María Oneide las muele. Por eso se dice que el aceite de babasú se "quema". Luego se lleva la pasta de almendras trituradas y se cocina con fuego de leña. Mientras hierve, el aceite "flota" y doña Eva "refina" todo el aceite de babasú y lo recoge con mucho cuidado y precisión para que doña María Oneide lo embotelle. El aceite está entonces listo para su uso y comercialización. La Familia de Doña Eva nos sorprendió con una "farofa de gongo" (harina de yuca tostada) con el chinche del coco (Pachymerus nucleorum), una larva de escarabajo brúquido que vive en los frutos de la palma babasú, frito por supuesto, en el propio aceite de babasú.

Así, recorrimos y delimitamos los lugares de actividad económica y los conocimientos y prácticas acerca de la extracción de babasú y sus subproductos por parte de estas mujeres. Observamos sus relaciones sostenibles con la naturaleza y cómo de urgente resulta la comprensión del proceso para la preservación de este bello patrimonio cultural y ambiental (Pelegrini, 2006).

\section{Referências:}

PELEGRINI, Sandra C. A. Cultura e natureza: os desafios das práticas preservacionistas na esfera do patrimônio cultural e ambiental. Revista Brasileira de História, São Paulo, V. 26, nº 51, p. 115-140, 2006.

SILVA, Fabíola Andréa. Etnoarqueologia: uma perspectiva arqueológica para o estudo da cultura material. Métis: história \& cultura, v. 8, n. 16, 2009.

Palavras-chave: MULHERES QUEBRADEIRAS DE COCO BABAÇU, ETNOGRAFIA, PATRIMÔNIO CULTURAL E ORALIDADE, TERRITÓRIO ENTRE RIOS, NORDESTE DO BRASIL.

PALABRAS CLAVE: MUJERES ROMPEDORAS DE COCO BABASÚ, ETNOGRAFÍA, PATRIMONIO CULTURAL Y ORALIDAD, TERRITÓRIO ENTRE RIOS, NORDESTE DE BRASIL. 


\section{AUTORES:}

Aline Gonçalves de Freitas1, Ana Luisa Meneses Lage do Nascimento2, Paulo Sergio da Paz Filho3

Agradecimentos/Agradecimentos: a todas as pessoas da Comunidade Fazenda Soares, em especial à Dona Maria Oneide, Dona Eva, Dona Francisca e Senhor Antônio, que nos auxiliaram em todas as etapas de campo, com vossos carismas e gentileza.

1 Universidade Federal do Piauí, Centro de Ciências da Natureza 2, Programa de Pós-Graduação em Arqueologia. Bolsista de Pós-Doutorado. E-mail: aline.goncalves@ufpi.edu.br. . ORCID: https://orcid.org/0000-0001-5450-0850. https://orcid.org/0000-0002-6953. -4065 .

2 Universidade Federal do Piauí, Centro de Ciências da Natureza 2, Programa de Pós-Graduação em Arqueologia. Professora Adjunta E-mail: analage@ufpi.edu.br. ORCID: https://orcid.org/0000-0002-6953-4065.

3 Universidade Federal do Piauí, Centro de Ciências da Natureza 2, Curso de Graduação em Arqueologia. Aluno de Graduação. E-mail: sergiopaulopaz@gmail.com. ORCID: https://orcid.org/0000-0002-1011-6280.
Ficha técnica:

Direção, pesquisa e edição/ Dirección, investigación y edición: Aline Gonçalves de Freitas, Paulo Sergio da Paz Filho e Ana Luisa Meneses Lage do Nascimento.

Fotografia/ Fotografía: José Ailson Nascimento Sousa (UmZé).

Período de registro/ Periodo de registro: novembro de 2019. 